\section{Nature of Acid in Soft Water in Relation to the Growth of Brown Trout}

Is 1937 I made a brief survey of some small lochs in Sutherland, in some of which the water was fairly acid $(p H 4 \cdot 5)$. I found, as Captain Sawyer ${ }^{1}$ has done, that the $p \mathrm{H}$ of these waters could be changed very rapidly towards neutrality by shaking with air; and $I$ concluded, like him, that the acidity was due mainly, if not entirely, to dissolved carbon dioxide.

An account of these observations was given to the British Association in $1937^{2}$, and my deductions as to the cause of the acidity were criticized on chemical grounds. Later, further samples from these lochs were collected and were examined by the Government Chemist. He reported (in literis) that the water was acid, that the $p H$ was not noticeably altered by aeration and that the acidity was due to a small quantity of a strong acid, of vegetable or peaty origin, in solution. That the $p \mathbf{H}$ of these samples could not be changed by aeration made me suspect that conditions in these lochs had changed and, by correspondence, I ascertained that this was so. The samples examined by the Government Chemist were taken after a period of heavy rain and were brown in colour, whereas mine were taken after some weeks of drought and were virtually colourless. It was hoped to continue these observations, but a change of programme and then the War have so far made it impracticable.

The conclusion is that Captain Sawyer has produced supporting evidence for the view that the acidity of the waters of these lochs may at times be due to carbon dioxide, but that the presence and importance of 'humic' acids can by no means be ignored.

Whether these factors have any direct bearing on the varying sizes attained by trout in different waters is open to considerable doubt. When Southern ${ }^{3}$ produced the hypothesis that the growth of trout was directly related to the composition of the water in which they were living, he started a hare which many of us have followed for varying distances. I now believe that the solution of the problem is to be sought in the relation between the trout population and the food supply. That this line of attack has formerly been found to be unpromising 4.5 is due to over-emphasis of the latter factor and neglect of the former. It happens that, in soft or acid waters, spawning conditions for trout are often ideal, for the rocks are hard and the redds are consequently free from silt. Hence the percentage hatch is large ${ }^{6}$ and the survival-rate continues to be high because the predatory fishes such as pike, perch and chub are absent from such waters. The pressure on the available food is accordingly great, and trout, with their extraordinary lability, respond to the conditions by a general decrease in growth.

In waters where the survival-rate is low, owing either to poor spawning ground or to the presence of predators, the trout grow big, whether the water is acid or alkaline ${ }^{3}$.

It is hoped, when time permits, to develop this thesis in a paper in Biological Reviews.

\section{F. T. K. Pentelow.}

\section{Old Slade Lane,}

Iver, Bucks.

1 Sawyer, R. E., NATURE, 153, 55 (1944)

2 Pentelow, F. T. K., Rep. Brit. A 8soc. Adv. Sci., 364 (1937)

${ }^{3}$ Southern, R., Salm. Trout Mag. Lond., Nos. 67, 68, 69 (1932).

- Southern, R., Proc. Roy. Irish Acad., 42, 87 (1934-35).

- Frost, W. Proc. Roy. Irish Acad, 45, 139 (1938-40).

- Hobbs, D. F., New Zealand, Marine Dept., Fish. Bull., 6 (1987).

\section{Achilles and the Tortoise}

Prof. F. G. Donnan has submitted ${ }^{1}$ a very interesting application of the exponential function. I think, however, that his first equation is not altogether accurate. I suggest that the following is rather more realistic.

If $y$ and $x$ are the distances of Achilles and the tortoise from a fixed datum, then

$$
\frac{d y}{d t}=10 p e^{-\lambda t} ;
$$

when $t=0, y=0$ and the constant of integration will be $10 p / \lambda$ and

$$
\begin{gathered}
y=\frac{10 p}{\lambda}\left(1-e^{-\lambda t}\right) . \\
\frac{d x}{d t}=p e^{-\lambda t} ;
\end{gathered}
$$

when $t=0, y=d$, their distance apart at the start.

So that the constant of integration is $\frac{p}{\bar{\lambda}}+d$, and $x=d+\frac{p}{\lambda}\left(1-e^{-\lambda t}\right)$.

If $D$ is their distance apart after time $t$,

$$
D=x-y=d-\frac{9 p}{\lambda}\left(1-e^{-\lambda t}\right) ;
$$

when $t=\infty, D=d-\frac{9 p}{\lambda}$.

So $D$ may be positive, negative or zero, which rather disproves Zeno's paradox.

Vincent House,

G. SILYN Roberts.

Pembridge Square,

London, W.2.

I.NATURE, 153, 142 (1944).

ThE statement of Group-Captain G. S. Roberts, that the first equation in my letter to NATURE to which he refers "is not altogether accurate", would appear to mean that it does not cover the general case of a tortoise with any possible start. It was made clear in my letter, however, that this equation applies only to the case of a tortoise with a specified start, namely, 10 units of distance. In this particular case I showed how it was possible, by a special adjustment of the ratio $p / \lambda$, to secure the result that Achilles would overtake this particular tortoise only in an infinite time. Given this particular (adjusted) value of $p / \lambda$, it follows that, for tortoises travelling according to the same law of speed, those with a start of less than 10 will be overtaken in a finite time, whereas those with a start of greater than 10 would not be overtaken by Achilles even in an infinite time.

It is, of course, a very simple matter to give a general algebraic statement valid for tortoises with all possible starts, but I did not consider that the interest, of the problem warranted any further elaboration. It was, however, amusing to note that by a suitable adjustment of $p / \lambda$ one could always make a 'cut' in the infinite set (of tortoises). This point has been well taken in an interesting letter which I have received from $\mathrm{Mr}$. W. J. Chater of Northampton.

F. G. Donnan.

The Athenæum,

London, S.W.I. 